EPJ Web of Conferences 92,02102 (2015)

DOI: $10.1051 /$ epjconf/ 20159202102

C Owned by the authors, published by EDP Sciences, 2015

\title{
The experimental study of the features of water flowing through a sharp- crested weir in channel
}

\author{
Dinara Turalina $^{1}$, Dinara Yembergenova ${ }^{1}$ and Karlygash Alibayeva ${ }^{1}$ \\ ${ }^{1}$ Department of Mechanics and Mathematics, Al- Farabi Kazakh National University, Kazakhstan
}

\begin{abstract}
This article contains the experimental research of water flowing through a weir in a rectangular open channel. Nine regimes of water flowrate investigated in this study. Upstream water levels partially determined for each regime. The coefficient of discharge to the weir determined from the flowrate equation. The determined coefficient of discharge value compared to the value from the Rehbock formula. The diagram of values shows the dependence of the coefficient of discharge $\mathrm{Cd}$ on the upstream water level $\mathrm{y}_{\mathrm{c}} / \mathrm{h}$. Experimental study conducted on the Armfield S16 hydraulic flow demonstrator and hydraulic bench F1-10.
\end{abstract}

\section{Introduction}

Nowadays there are only several hydroelectric power stations which operating modes are based on a highpressure system. The system helps to provide the safety on the HES from emergencies, by ventilating the nappe.

Hydro-technical constructions are: hydroelectric station's constructions, weirs, spillways etc., which are designed to provide the safety from floods, flood- tide, dam break, and streamline erosion. The weir is a barrier, a bound with free flowing. Hydroelectric stations are built on rivers, constructing dams and water reservoirs. The HES provides required water pressure coming to the blade of the turbine, which turns generators to produce the energy. That is why the ventilation process of a weir must be constructed. The ventilation process increases the flowrate flowing frequency over the weir. At a high flowrate the nappe tends to cling to the surface of the weir, interrupting free discharge of flowing.

Characteristics of Armfield S16 hydraulic flow demonstrator and hydraulic bench F1-10 (figure 1).

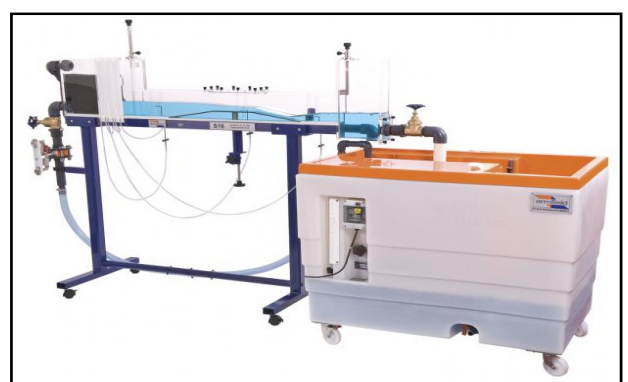

Figure 1. Armfield S16 hydraulic flow demonstrator, F1-10 hydraulics bench.
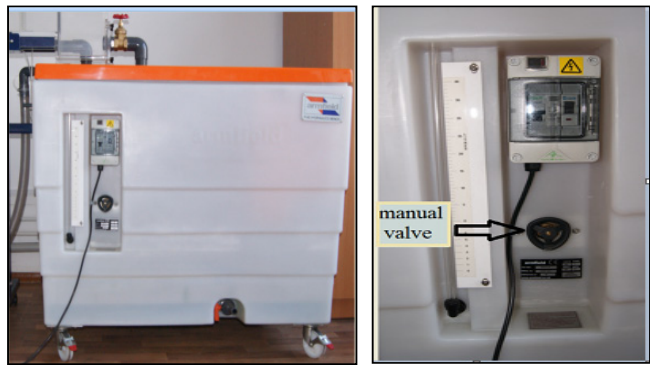

Figure 2. F1-10 volumetric tank.

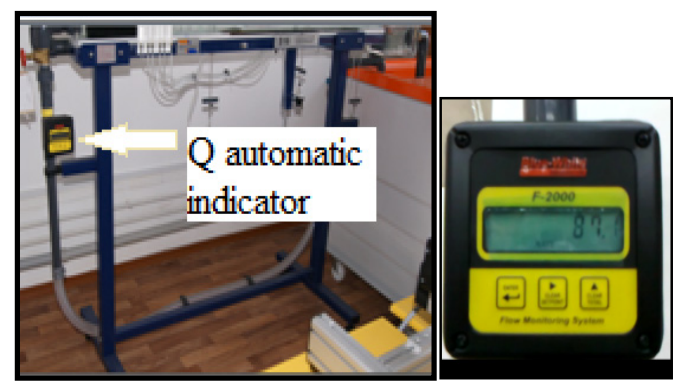

Figure 3. S16 demonstrator.

Airfield S16 hydraulic flow demonstrator consists of following constructions: three Pitot and three Prandtl tubes; rising bed at the working section; 2 rising sluices at the inlet and at the outlet of channel, which are constructed with clear acrylic sides; 2 flexible tubes, at the inlet, the outlet discharge.

The Armfield S16 equipment parameters are: height $-1.60 \mathrm{~m}$, strength $-2.20 \mathrm{~m}$, width $-0.63 \mathrm{~m}$, weight (dry) - $100 \mathrm{~kg}$. S16 with F1 - 10: height - $1.60 \mathrm{~m}$, length $-3.00 \mathrm{~m}$, width $-0.90 \mathrm{~m}$. Length of working 
section $-1100 \mathrm{~mm}$, width $-77 \mathrm{~mm}$, height $-150 \mathrm{~mm}$, height of inlet and discharge tank - $340 \mathrm{~mm}$.

The F1-10 volumetric tank parameters are: strength - 1,13 m; width - 0,73 m; height - 1,00 m. Centrifugal typed tank, top point of water level $-21 \mathrm{~m}$, operating flow range $-80 \mathrm{l} / \mathrm{s}$, motor power $-0,37 \mathrm{~kW}$, capacity 2501 .

The weir parameters: weir width $b=0,077 \mathrm{~mm}$; weir height $\mathrm{h}=0,075 \mathrm{~mm}$; crest width $=2 \mathrm{~mm}$.

\section{The experimental research}

The crest of a sharp-crested weir separates the flow into two- dimensional jet, nappe (figure 4). The nappe at a high flowrate starts to cling to the surface of the weir. The flowing water under the nappe entrains air into the cavitation. When flowrate increases too high, the pressure over the weir will decrease. This causes more water to be drawn; therefore the discharge over the weir will increase. The pressure inside of a cavitation tends to decrease; it causes a curvature of the flow. The nappe springs freely, when the pressure over the weir is hydrostatic [3].

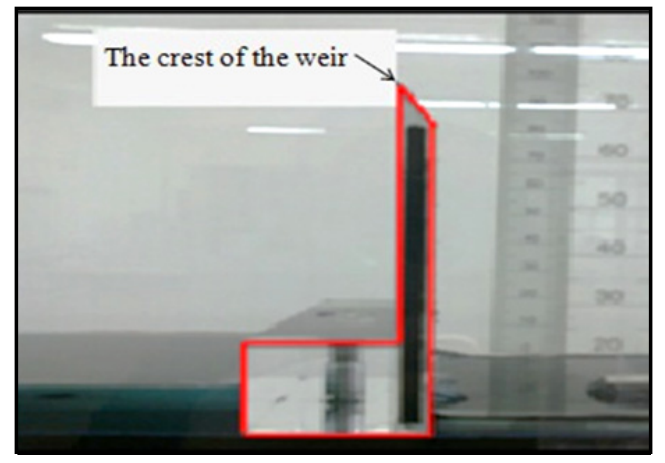

Figure 4. A sharp-crested weir shape.

The coefficient of discharge $C_{d}$ determined from the flowrate $Q$ equation for a rectangular sharp-crested weir an open channel flow for experimental values

$$
\begin{gathered}
Q=\frac{2}{3} \cdot C_{d} \cdot b \cdot(2 g)^{\frac{1}{2}} \cdot y_{c}^{\frac{3}{2}} \\
C_{d}=\frac{Q}{\frac{2}{3} \cdot b \cdot(2 g)^{\frac{1}{2}} \cdot y_{c}^{\frac{3}{2}}}
\end{gathered}
$$

The coefficient of discharge $C_{d}$ determined from the Rehbock formula for analytical values [5]

$$
C_{d}=0.602+0.083 \cdot \frac{y_{c}}{h}
$$

Experimental values of the coefficient of discharge are compared to analytical results (3).
Owing to free springing nappe, the weir is not drowned when $\frac{y_{c}}{h} \leq 5$, then $y_{c o}=y_{c}$. When $\frac{y_{c}}{h} \geq 0,5$, the weir is $\quad$ suppressed, $\quad y_{c o}=y_{c}+\frac{\vartheta^{2}}{2 g}$; $\vartheta=\frac{Q}{\left(b\left(y_{c}+h\right)\right)} ; \vartheta$ - upstream head velocity; $y_{c o}$ - total discharge over the weir [2].

Flowrate $Q$ has been taken from $\mathrm{S} 16$ demonstrator indicator supplied to F1-10 volumetric tank. S16 demonstrator indicator shows the flowrate for $1 / \mathrm{min}$ and can be increased by F1-10 tank by manual valve (figure 2 , figure 3). In each regime, the step of water level increased for $5 \mathrm{~mm}$ above the crest of the weir.

This experimental study investigates nine regimes. From the $1^{\text {st }}$ to the $7^{\text {th }}$ regime, the weir is not drowned (figure 5), the nappe is depressed weir is drowned at the last two regimes. When the weir is not drowned, then $y_{c 0}=y_{c}$, for the suppressed weir, $y_{c 0}=y_{c}+\frac{\vartheta^{2}}{2 \cdot g}$

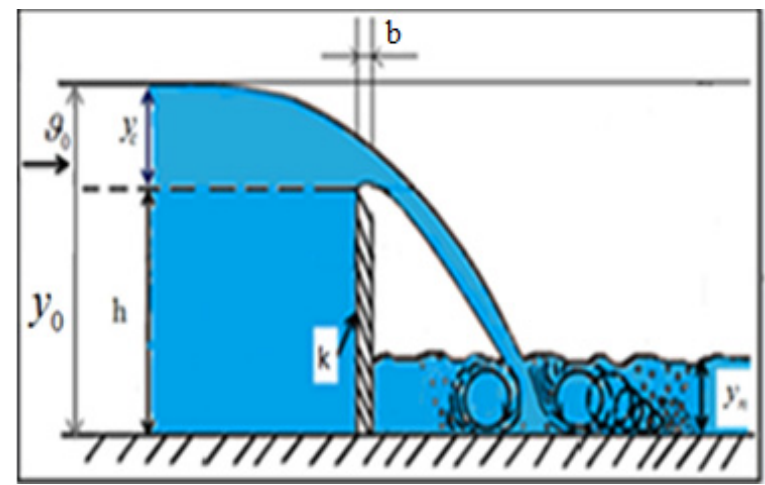

Figure 5. A sharp- crested weir scheme:

$y_{\mathrm{C}}$ - upstream height above the crest of the weir or total discharge over the weir; $h$ - height of weir; $y_{0}$ - upstream height of weir; $k$ - the crest of a weir; $y_{\eta}$ - downstream height of weir; $b$ - width of weir.

The pressure within this cavity through the weir decreases, and this leads to the nappe vibration. In this case the nappe is suppressed.

The nappe can take 4 forms: springing, depressed, drowned, clinging.

Owing to increased flowrate, hydraulic jump act to the nappe. It leads the nappe to cling to the weir surface. The nappe is suppressed in this case. Within this, a cavity decreases in a volume; it is caused by low pressure.

When the downstream head rises to the weir height, then the nappe is depressed. This can leads later to the drowned nappe and increases the discharge over the weir. The pressure inside the flow over the weir is lower than the pressure in front, flowing water reduces the pressure over the weir and the pressure in a cavitation decreases. 
If the ventilated process of the nappe is not provided, then the discharge to the weir increases. The nappe is depressed. Further, in such dangerous situations, the whole volume of water will occupy the cavitation. When a hydraulic jump acts to unventilated nappe, the downstream head quickly rises to the height of the weir. Then a hydraulic jump will cling to the nappe, which leads the downstream head to rise to the top of the weir. This form of the nappe is called drowned.

When the nappe is not ventilated, it will be depressed, and the discharge will increase from 6 to $7 \%$ more than the value given by the formula. The discharge also increases, and can be more than $20 \%$ the formula [4].

To provide the safety on GES, the ventilation process must be provided by pipes below the nappe through the channel walls, which will withdraw the lower pressure to atmosphere.

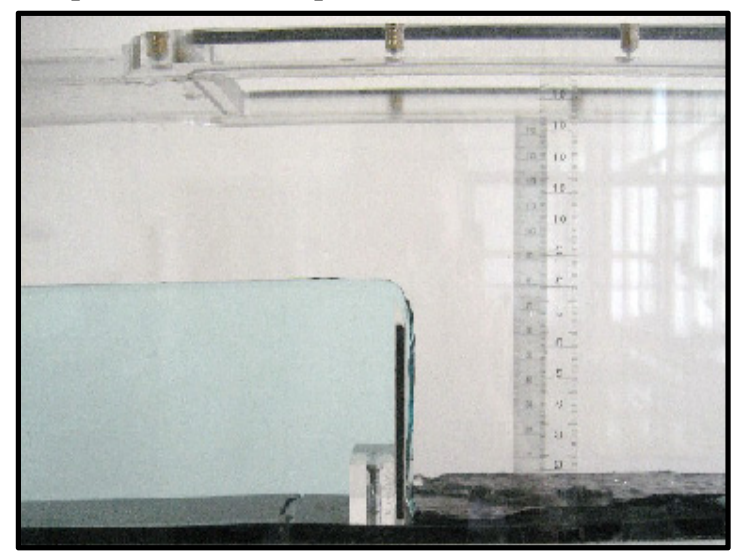

Figure 6. A water regime over a sharp crested weir.

\section{Experiment results}

Obtained results show the dependence of a water flowrate Q on the upstream head $y_{O}$. Results illustrated in pictures of a water flowrate for nine regimes.

1) $y_{0}=0.08 \mathrm{~m}, Q=0.06 \mathrm{l} / \mathrm{min}$. The water flow freely springs over the weir surface, the difference between two heads are considerable (figure 6).

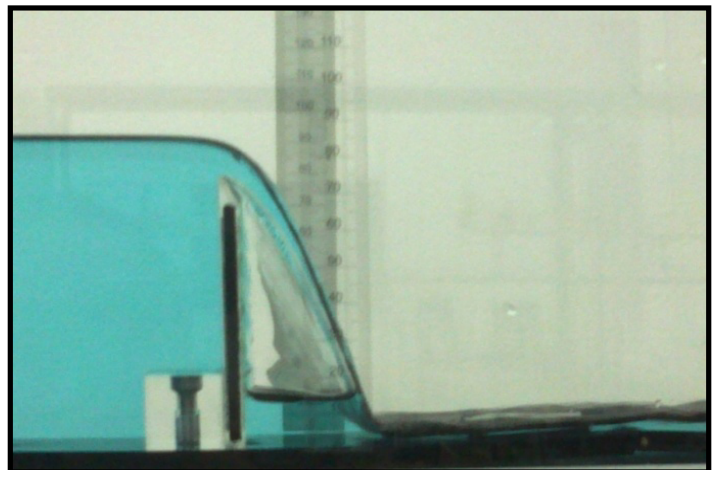

Figure 7. A water regime over a sharp crested weir.

2) $y_{0}=0.085 \mathrm{~m}, Q=0.13 \mathrm{l} / \mathrm{min}$. The water flow freely springs over the weir surface. The cavitation has appeared over the weir, it causes increasing of flowrate (figure 7).

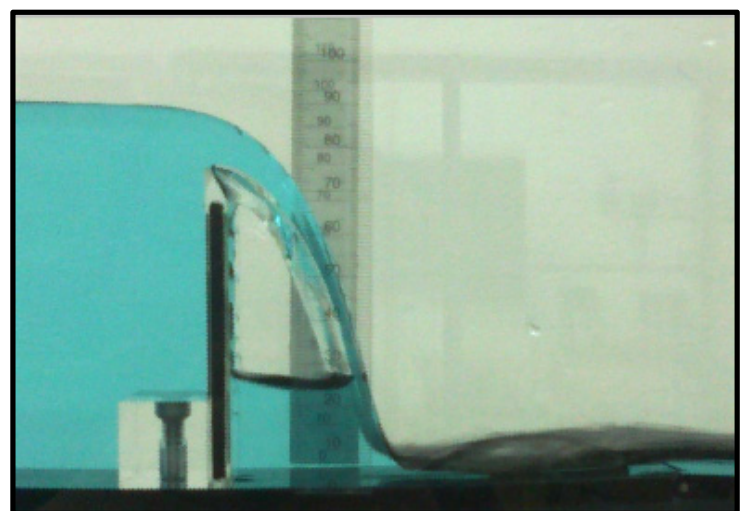

Figure 8. A water regime through a sharp crested weir.

3) $y_{0}=0.09 \mathrm{~m}, Q=0.2 \mathrm{l} / \mathrm{min}$. The pressure at the cavitation starts to decrease in a volume, and causes increasing of flowrate (figure 8).

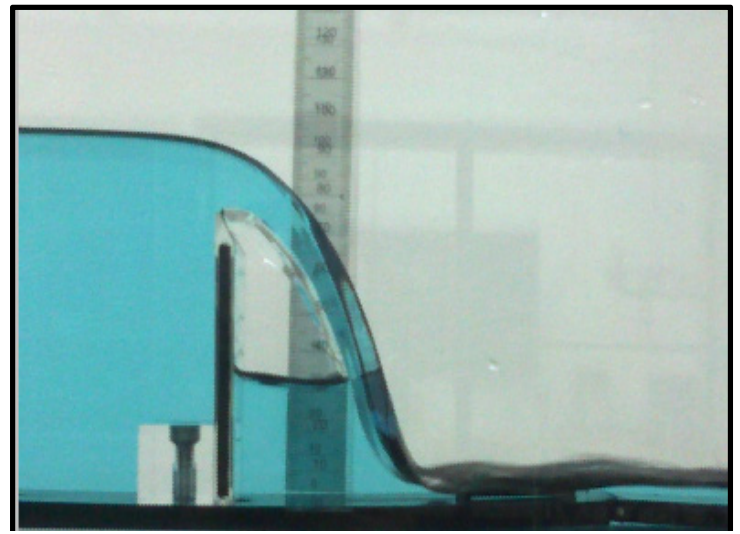

Figure 9. A water regime over a sharp crested weir.

4) $y_{0}=0.85 \mathrm{~m}, Q=0.26 \mathrm{l} / \mathrm{min}$. The nappe at the end of the weir clings to the weir surface. The pressure decreases inside of the cavity. Owing to low pressure, the cavity reduces a volume (figure 9).

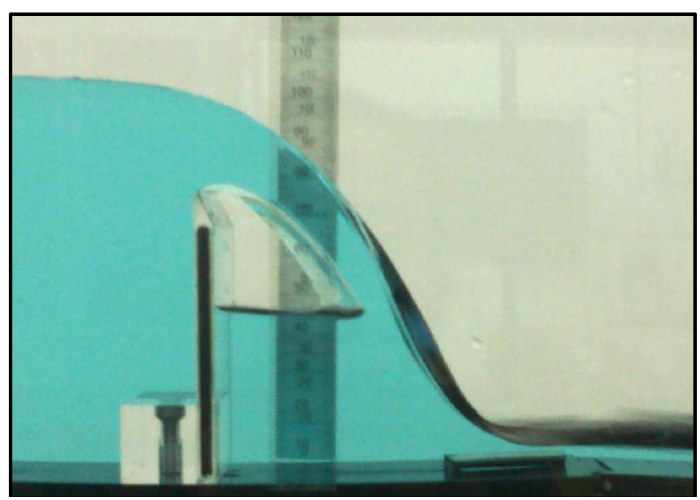

Figure 10. A water regime over a sharp crested weir.

5) $y_{0}=0.105 \mathrm{~m}, Q=0.33 \mathrm{l} / \mathrm{min}$. The nappe at the end of the weir clings to the weir surface. Owing to low pressure the cavity is reduced in volume, discharge over weir is increasing (figure 10). 


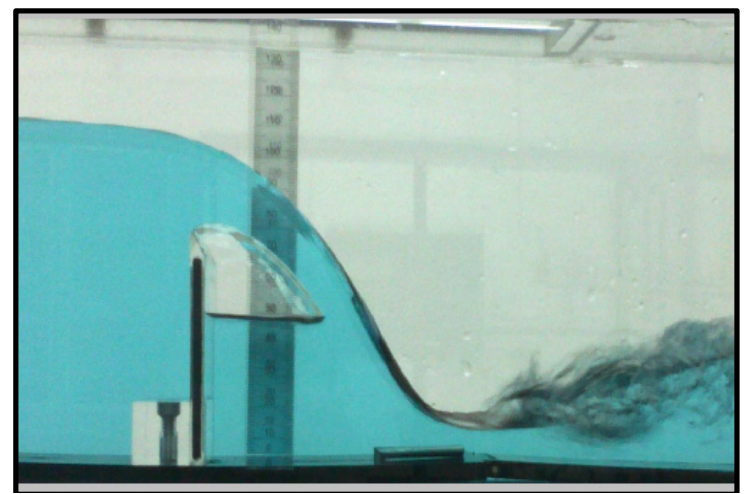

Figure 11. A water regime over a sharp crested weir.

6) $y_{0}=0.105 \mathrm{~m}, Q=0.4 \mathrm{l} / \mathrm{min}$. The nappe at the end of the weir does not spring freely. The downstream head tends to bend the upstream head through the weir. Thus, the volume of a cavity decreases. The pressure inside of the cavity is less than hydrostatic pressure (figure 10). Hydraulic jump circulate against to a water flow, what tends water quickly rise to the crest of weir [4].

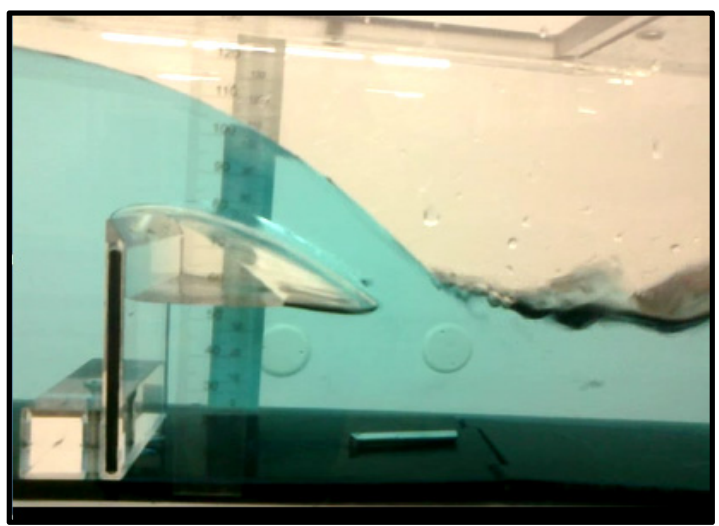

Figure 12. A water regime over a sharp crested weir.

7) $y_{0}=0.105 \mathrm{~m}, \mathrm{Q}=0.46 \mathrm{l} / \mathrm{min}$. The nappe at the end of the weir does not spring freely. Downstream head interrupting the flow at the upstream head, thus the pressure inside of the cavity tends to decrease. The cavitation is near to partially pullet out of the weir (Figure 11).

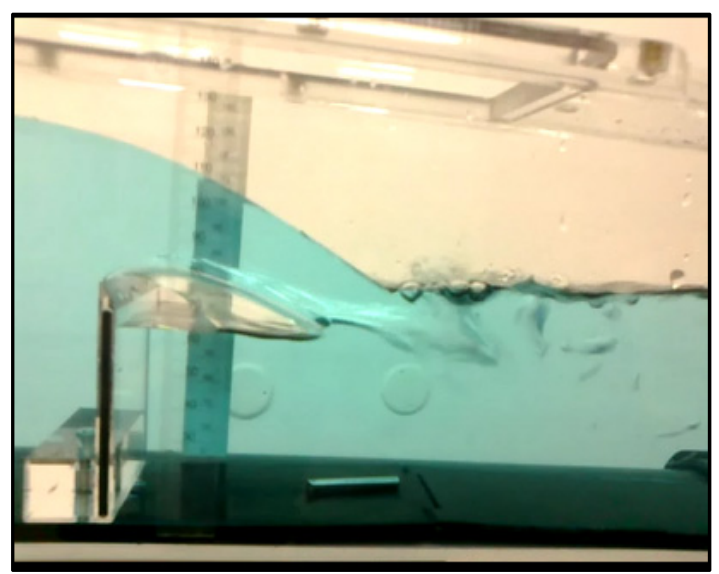

Figure 13. A water regime over a sharp crested weir.
8) $y_{0}=0.115 \mathrm{~m}, Q=0.53 \mathrm{l} / \mathrm{min}$. The whole volume of the cavitation is near to sweep out of the weir, cause of hydraulic jump operating [1]. The figure 12 shows the easily rising of the downstream head to the weir top. This leads later that the downstream flow is involved to the upstream head. The downstream head interrupts the rapid flow, case of a superfluity kinetic energy of water volume through an upstream head (figure 13).

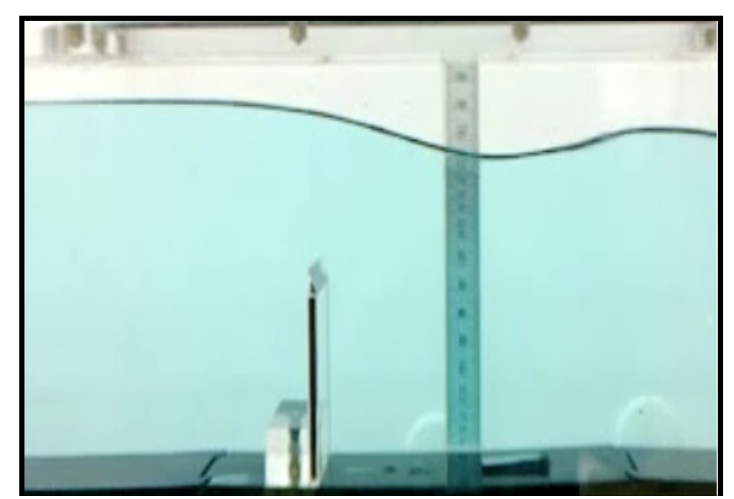

Figure 14. A water regime over a sharp crested weir.

9) $y_{0}=0.12 \mathrm{~m}, Q=0.6 \mathrm{l} / \mathrm{min}$. The cavitation through the downstream head pulled out the nappe from the weir. The weir is drowned (figure 14).

Table 1. The dependence of coefficients of discharge, of experimental result and the Rehbock formula to the upstream water level.

\begin{tabular}{|c|c|c|c|c|c|c|}
\hline No & $\mathbf{Q}\left(\mathbf{m}^{\wedge} 3 / \mathrm{s}\right.$ & yc & $\mathrm{yc}^{\wedge} 3 / 2$ & $\mathbf{y c} / \mathbf{h}$ & Cd (exp) & Cd (Rehb.) \\
\hline 1 & $1,7 \mathrm{E}-05$ & 0,005 & 4E-04 & $\mathbf{0 , 0 7}$ & 0.14 & 0.6 \\
\hline 2 & 3,3E-05 & 0,01 & $\mathbf{0 , 0 0 1}$ & $\mathbf{0 , 1 3}$ & 0.62 & 0,613 \\
\hline 3 & 0,00005 & 0,015 & 0,002 & 0,2 & 0.614 & 0.618 \\
\hline 4 & $6,7 \mathrm{E}-05$ & 0,02 & $\mathbf{0 , 0 0 3}$ & 0,27 & 0.615 & 0.624 \\
\hline 5 & 8,3E-05 & 0,025 & 0,004 & $\mathbf{0 , 3 3}$ & 0.644 & 0.629 \\
\hline 6 & 0,0001 & $\mathbf{0 , 0 3}$ & 0,005 & 0,4 & 0.63 & 0.635 \\
\hline 7 & $\mathbf{0 , 0 0 0 1 2}$ & 0,035 & $\mathbf{0 , 0 0 7}$ & $\mathbf{0 , 4 7}$ & 0.638 & 0,64 \\
\hline 8 & $\mathbf{0 , 0 0 0 1 3}$ & 0,04 & 0,008 & $\mathbf{0 , 5 3}$ & 0.714 & 0.646 \\
\hline 9 & 0,00015 & 0,045 & 0,01 & 0,6 & 0.687 & 0.651 \\
\hline
\end{tabular}

The comparison of experimental results of the coefficient of discharge $\mathrm{Cd} 1$ and results obtained from the Rehbock formula $\mathrm{Cd} 2$ is presented in figure 15 . The comparison shows that experimental and analytical results are near to coincide from the $2^{\text {nd }}$ to the $5^{\text {th }}$ regimes. Cause of the nappe is not depressed. The $1^{\text {st }}$ regime is far down to the analytical, cause of the flowrate, which must be high increased to raise the next regime. The $6^{\text {th }}$ and the $7^{\text {th }}$ regimes show increasing of the flowrate, which leads to the discharge of increasing over the weir. The nappe is clinging to the surface of the weir - unventilated nappe. The $8^{\text {th }}$ and the $9^{\text {th }}$ regimes show the reasonably high flowrate increasing. This increases the discharge over weir. The pressure is decreasing, cause of no cavitation over weir, then the discharge easily drown the weir and the nappe is 
drowned. In extreme cases increased discharge over weir can destroy the weir construction.

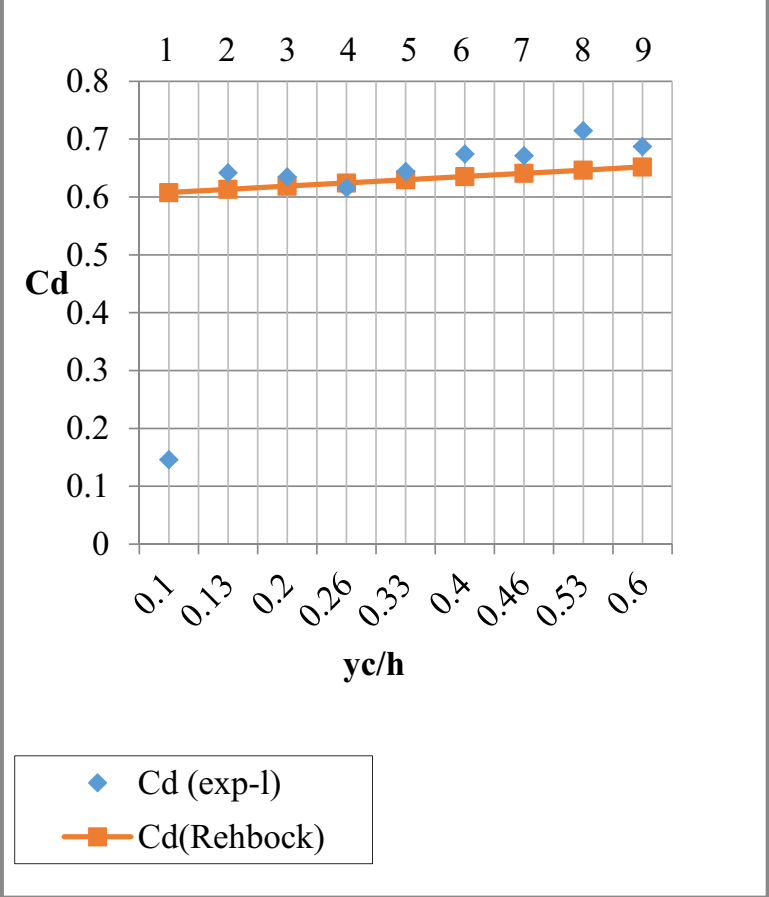

Figure 15. The dependence of the upstream head different $\mathrm{yc} / \mathrm{h}$ to the coefficient of discharge Cd through the weir. Cd1experimental results; $\mathrm{Cd} 2$ - results from the Rehbock formula.

\section{Conclusions}

The figure shows the change of discharge characteristics of the weir. Such behavior acted when the pressure over weir is decreasing and reducing. Cause of more water to be drawn. If the nappe is ventilated, the pressure will increase and the hydraulic jump could not suppress the weir at reasonably high flowrate. That is the way to keep safety on the HTC. The nappe will freely springs to the surface of the weir. If no provision is supply then the hydraulic jump will draw the cavitation out of the weir.

The nappe can be ventilated by pipes, open to atmosphere. Which will withdrawal the low pressure. In extreme cases the drowned weir can leads to the stream erosion, dam break.

\section{References}

1. Hinge G.A., Balkrishna S., Khare K.C., Improved Design of Stilling Basin for Deficient Tail Water, J. Basic. Appl. Sci. Res., 31-32, 1(1), (2010)

2. Hadi A., Navid N.O., Sharp-Crested Weir Discharge Coefficient, Sci. pub-n, J. Civil Eng. Urban., 87-91, 3(3), (2011)

3. Emad Abdul Gabbar Al Babely, Behaviour of the discharge coefficient for the Overflow characteristics of oblique circular weirs, Tikrit J.Eng. Sci., 55-64, V 19, №4, (2012)
5. Instruction manual, Hydraulic flow demonstrator (Closed and Open Channel Flow), Armfield, S16, Issue 3, England, 89-91, (2011)

4. I.V. Bukreyev, Ondulyarnyi pryzhok pri obtekanii otkrytym potokom poroga $v$ kanale (hydraulic jump flowing over open sill in channel). Appl. Mech. and Tech. Phys., Tomsk, 42, №4, (2001) 